\title{
Adenoma detection rate as a quality indicator for colonoscopy: a descriptive cross-sectional study from a tertiary care hospital in Pakistan
}

(๑) $\odot \ominus$

\author{
Authors \\ Institutions \\ 1 Section of Gastroenterology, Department of Medicine, \\ Aga Khan University, Karachi, Pakistan \\ 2 Medical College, Aga Khan University, Karachi, Pakistan \\ 3 General Surgery, Department of Surgery, Aga Khan \\ University, Karachi, Pakistan
}

Mian Shah Yousaf ${ }^{1}$, Shameel Shafqat ${ }^{2}$, Roger Christopher Gill ${ }^{3}$, Asfia Arham Khursheed ${ }^{3}$, Om Parkash ${ }^{1}$ stan. submitted 9.3.2020

accepted after revision 30.7 .2020

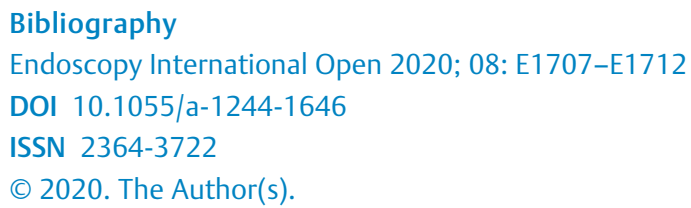
Commons Attribution-NonDerivative-NonCommercial License, permitting copying and reproduction so long as the original work is given appropriate credit. Contents may not be used for commecial purposes, or adapted, remixed, transformed or built upon. (https://creativecommons.org/licenses/by-nc-nd/4.0/)

Corresponding Author

Dr. Om Parkash MBBS, FCPS, FCPS, Section of

Gastroenterology, Department of Medicine, Aga Khan

University, Karachi 74800, Pakistan

Phone: +923333509749

om.parkash@aku.edu

\section{ABSTRACT}

Background and study aims Adenoma detection rate $(A D R)$ is validated for measuring quality of colonoscopy, however there is lack of colorectal cancer (CRC) screening program in South Asia. The purpose of this study is to analyze and review the polyp detection rate (PDR) and ADR and provide insight into the factors that influence them in Paki-

Patients and methods This retrospective, cross-sectional study was performed at the Aga Khan University Hospital, Karachi, Pakistan, on patients $\geq 18$ years, who underwent colonoscopy between January 1, 2017 and June 30, 2018.

Results of 1985 patients, $59 \%$ were male and $41 \%$ female, with mean age of $47.8 \pm 16.2$ years. The most common indication for colonoscopy was bleeding-per-rectum (28.0\%) and overall PDR and ADR were $17.9 \%$ and $9.9 \%$, respectively. There was no significant difference between genders for either PDR $(P=0.378)$ or ADR $(P=0.574)$. Significantly higher PDR and $A D R$ were found for patients $\geq 50$ years $(P<$ 0.001 ), as well as for suboptimal bowel preparation [PDR (25.7\%; $P=0.007)$ and ADR (18.6\%; $P=0.014)$ ]. Interestingly, endoscopists with $<500$ colonoscopy-procedural-experience reported a higher PDR $(21.6 \% ; P=0.020)$ and ADR (14.4\%; $P=0.049)$, corresponding to a significantly higher $\operatorname{PDR}(20.6 \% ; P=0.005)$ and $\operatorname{ADR}(11.7 \% ; P=0.02)$ for endoscopists in practice for $\leq 10$ years.

Conclusions We have noticed low PDR and ADR, which require further investigation and research. In addition, we believe there should be a different baseline ADR and PDR as a quality indicator for colonoscopy in our region, where no internationally recommended colonoscopic screening programs have been implemented.

\section{Introduction}

Colorectal cancer (CRC) is considered the second most common cause for cancer mortality, and is one of the top three most prevalent cancers worldwide [1]. Screening programs for CRC have been implemented in many nations because of the documented association between screening and a sustained reduction in colorectal cancer mortality [2-4]. This benefit is most likely attributed to surveillance of patients either treated for CRC or with in whom it is detected early and subsequently removed endoscopically $[5,6]$.

The gold standard for CRC screening is colonoscopy, for its dual role as a diagnostic as well as therapeutic intervention in detection and removal of adenomas and their premalignant lesions [7,8]. However, the effectiveness of colonoscopy is strongly associated with its quality, which is characterized by key standard quality indicators (QI) [9]. Among these are cecal 
intubation rate, withdrawal time, quality of bowel preparation, and adenoma detection rate (ADR).

ADR is most frequently used quality indicator and is now designated as an outcome measure of colonoscopy; it is defined as the proportion of screening colonoscopies in patients $\geq 50$ years, detecting at least one adenoma or adenocarcinoma, and should ideally be $\geq 25 \%$. There is compelling evidence to support an inverse correlation between ADR and interval CRC (cancer detected after a screening colonoscopy), which has the potential to lower future mortality from CRC [10]. This is supported by Corley et al, which states that for every $1 \%$ increase in $A D R$, there is a $3 \%$ predicted decrease in interval CRC (hazard ratio 0.97; $95 \%$ Confidence Interval $(\mathrm{Cl}), 0.96-0.98)$, and a $5 \%$ decrease in risk of fatal interval CRC (hazard ration 0.95; $95 \%$ $\mathrm{Cl}, 0.94-0.97)$ [11]. Although the American Society of Gastrointestinal Endoscopy recommends that colonoscopists report their ADRs, current evidence suggests low-level detection, which endangers patients because effective polyp detection and resection help in CRC prevention [12]. Unfortunately, no standard CRC screening program exists in Pakistan, and no established measures have been taken to assess the quality of ADR measurement either.

Our study aimed to focus on and review the ADR of a tertiary care hospital in Pakistan, to provide insight into the ADR and quality of colonoscopy, and the factors that affect it, pertinent to this region of the world.

\section{Patients and methods}

We performed a retrospective observational study on patients aged $\geq 18$ years who underwent colonoscopy at the Aga Khan University Hospital (AKUH), Karachi, between July 1, 2017 to June 30, 2018. AKUH is a 740-bed private hospital situated in Karachi and one of the largest tertiary care centers in Pakistan. Exemption was acquired from the Ethical Review Committee, and patient data were retrieved using the ICD-10 Coding System.

All colonoscopies were performed by gastroenterologists at AKUH. Patient preparation consisted of clear liquid diet for 24 hours prior to colonoscopy, and $45 \mathrm{~mL}$ of bowel preparation solution, given 6 hours apart. This solution was prepared at the AKUH Pharmacy and consisted of sodium phosphate monohydrate and sodium phosphate heptahydrate with preservatives. Patients were consciously sedated by giving 2 to $5 \mathrm{mg}$ midazolam and 2 to $3 \mathrm{mg}$ intravenous nalbuphine. Bowel preparation was classified into good, suboptimal/reasonable, and poor, on the basis of the Boston Bowel Preparation Scale (BBPS), which is a reliable measure of bowel preparation [13], although no scoring system was assigned. All colonoscopies at AKUH were performed using the OLYMPUS manufactured EVIS EXERA III video colonoscopes [CF-H190 L/I (Olympus Corp., Europe) and CF-HQ190 L/I (Olympus Corp., United States)]. Abnormal findings detected during colonoscopy were biopsied for further evaluation. Any and all polyps found were removed and biopsied for histopathology.

A predesigned proforma was used to collect variables such as age, gender, indication of colonoscopy, bowel preparation, colonoscopy findings, and histopathology reports. Patients who underwent sigmoidoscopy only were known cases of familial adenomatous polyposis, or had incomplete data were excluded.

Statistical analyses were carried out using SPSS V25.0, with continuous data reported as means \pm standard deviation (S.D.) [medians (range)], and categorical variables as gross numbers and percentages $(\mathrm{n}$; \%). Statistical significance of ADR (colonoscopies in which $\geq 1$ histologically confirmed adenoma and/or carcinoma) and PDR (colonoscopies in which $\geq 1$ polyp and/or growth or mass) was calculated using the Chi-squared test for categorical variables.

$P<0.05$ was considered significant for all analyses.

\section{Results}

A total of 1985 patients were included in the final sample, of which $59.0 \%$ (1172) were males and $41.0 \%$ (813) females, with a mean age of $47.8 \pm 16.2$ years $(48.0,19-88)$. The most common indication for colonoscopy in our patient population was bleeding-per-rectum [28.0\% (556)], and 94.4\% (1873) of patients had good bowel-preparations. The most common abnormal finding was hemorrhoids [425 (21.4\%)], with nonspecific colitis as the most frequent finding on histopathology [498 (25.1\%)]. Polyps were detected in only $12.5 \%$ (248) of colonoscopies, while $5.9 \%(118)$ and $4.0 \%$ (79) adenomas and carcinomas were found on histopathology, respectively. This data are presented in further detail in $>$ Table 1. Our overall PDR and ADR were calculated as 17.9\% (355/1985) and 9.9\% (197/1985), respectively. Although no significant differences for either PDR $(P=0.378)$ or ADR $(P=0.574)$ were found considering gender, there was a significant greater PDR and ADR in patients $\geq 50$ years (PDR: $24.8 \%, P<0.001$; ADR: $15.0 \%, P<$ 0.001). Furthermore, statistically higher PDR (25.7\%; $P=$ 0.007 ) and $\operatorname{ADR}(18.6 \% ; P=0.014)$ were found for patients with suboptimal bowel preparation [3.5\% (70)].

A total of 23 endoscopists performed colonoscopy at AKUH; we divided them into four groups, based on the number of colonoscopies performed by each endoscopist in the last 10 years [<500 (Group 1), 500-999 (Group 2), 1000-1500 (Group 3), and $>1500$ (Group 4)]. Twelve endoscopists were included in Group 1, five in Group 2, four in Group 3, and two in Group 4. In our cohort, groups 1, 2, 3 and 4 performed 10.5\% (208), $23.1 \%$ (458), $32.4 \%$ (644) and $34.0 \%$ (675) of the colonoscopies, respectively. Interestingly, the PDR and ADR were found to be significantly higher for endoscopists in Group 1 (PDR: $21.6 \% ; P=0.02$ and ADR 14.4\%; $P=0.049$ ).

In addition, we classified endoscopists based on the number of years of experience; 13 endoscopists had been in practice for $\leq 10$ years and 10 had $>10$ years of experience. Endoscopists in practice for $\leq 10$ years performed $43.5 \%$ of the colonoscopies (863) while those with $>10$ years' experience in the field performed the remaining $56.5 \%$ (1122). The PDR and ADR were found to be significantly higher for endoscopists in practice for $\leq 10$ years as compared to those with $>10$ years of experience (PDR: $20.6 \%$ versus $15.8 \%, P=0.005$; ADR: $11.7 \%$ versus $8.6 \%$, $P=0.02)$. 
- Table 1 Characteristics of Colonoscopy.

\begin{tabular}{|c|c|}
\hline Characteristics & $\begin{array}{l}\text { Total }(N=1985) ; \\
n(\%)\end{array}$ \\
\hline \multicolumn{2}{|l|}{ Indications for colonoscopy } \\
\hline - Bleeding per rectum & $556(28.0)$ \\
\hline - Loose stools & $264(13.3)$ \\
\hline - Screening & $154(7.8)$ \\
\hline - Constipation & $153(7.7)$ \\
\hline - Anemia & $152(7.7)$ \\
\hline - Altered bowel habits (mixed patterns) & $139(7.0)$ \\
\hline - Surveillance & $136(6.9)$ \\
\hline - Abdominal pain & $135(6.8)$ \\
\hline - Others ${ }^{1}$ & $296(14.9)$ \\
\hline \multicolumn{2}{|l|}{ Bowel preparation } \\
\hline - Good & $1873(94.4)$ \\
\hline - Suboptimal & $70(3.5)$ \\
\hline - Poor & $42(2.1)$ \\
\hline \multicolumn{2}{|l|}{ Colonoscopy findings } \\
\hline - Normal & $596(30.0)$ \\
\hline - Hemorrhoids & $425(21.4)$ \\
\hline - Polyp & $248(12.5)$ \\
\hline " Abnormal growth/mass & $107(5.4)$ \\
\hline - Colitis/proctitis & $315(15.9)$ \\
\hline - Diverticulosis & $71(3.6)$ \\
\hline - Ulcers (terminal ileum, colonic and rectal) & $223(11.2)$ \\
\hline \multicolumn{2}{|l|}{ Histopathology findings } \\
\hline - None (Normal) & $1094(55.1)$ \\
\hline - Non-specific colitis & $498(25.1)$ \\
\hline - Adenoma & $118(5.9)$ \\
\hline - Carcinoma & $79(4.0)$ \\
\hline - Polyp (hyperplastic/inflammatory/retention) & $76(3.9)$ \\
\hline - Others ${ }^{2}$ & $71(3.5)$ \\
\hline \multicolumn{2}{|c|}{$\begin{array}{l}\text { All categorical variables are reported as numbers (percentages). } \\
{ }^{1} \text { Indication for colonoscopy: melena, weight loss, inflammatory bowel dis- } \\
\text { ease/ crohn's disease, painful defecation, incontinence, and abnormal CT } \\
\text { scan. } \\
{ }^{2} \text { Histopathology: infectious colitis, solitary rectal ulcer, melanoma, lym- } \\
\text { phoma, granulomatous inflammation, lipoma, neuroendocrine tumor and } \\
\text { collagenous colitis. }\end{array}$} \\
\hline
\end{tabular}

These results are summarized in $\mathbf{~ T a b l e ~} 2$.

\section{Discussion}

Our focused study aimed to provide insight into the quality of colonoscopies performed in a part of the world where no routine colonoscopy screening program is available. We report a PDR and ADR of $17.9 \%$ and $9.9 \%$, respectively. Our PDR seems to be lower compared to Western populations, as demonstrated by Cooper et al., which reported a PDR of $23.9 \%$ to $35.7 \%$ [14]. This variation might suggest a lower population incidence of polyps or is a result of poor practices due to lack of a stringent criteria to follow QI in colonoscopy, as well as poor knowledge about the importance of these validated QI. Our lower PDR is supported by regional studies from Rehman et al. and Saleh et al., which report a PDR of $11.3 \%$ (57/505), and $7.9 \%$ $(28 / 354)$, respectively $[15,16]$. However, certain limitations such as a smaller sample size, and sub-standard cecal intubation rate of Rehman et al., might have contributed to missed lesions and overlooked positive detection within samples. Furthermore, no reports of ADR were present in either article, preventing us from conclusively inferring on the PDR and ADR of our population.

In addition, the lower ADR and PDR of our population may be due to a younger presenting age of patients, i.e. $47.8 \pm 16.2$ years. Although this supports decreasing the minimum recommended age of colonoscopy screening from 50 to 45 [17], it is lower than the age after which most people undergo screening colonoscopy for CRC [18]; this can contribute to missed diagnoses within our broad population. Both ADR and PDR were significantly higher in our patients $\geq 50$ years $(P<0.001)$, supporting that increasing age is a predictor of adenoma at colonoscopy [19].

Our study does not report a significant predominance of polyps based on gender $(P=0.378)$, contradicting reports from Cooper et al. which showed that PDR was higher in males $(P<$ $0.0001)$. Lee and colleagues from the United Kingdom found their ADR to be $46.5 \%$, which was similarly increased in the elderly (age $>65)(P<0.001)$, but comparatively higher in men $(52.9 \%)$ than in women $(36.5 \%)(P<0.001)$ [20], signifying the difference in results from our population. We are unable to conclude any biological plausibility for this difference in gender, warranting a more detailed look into the subjects themselves.

Another factor that affects the quality of colonoscopy, hence the ADR, is bowel preparation; it has been reported that approximately $20 \%$ to $25 \%$ of all colonoscopies are in patients who have poor or inadequate bowel preparation, leading to multiple adverse events, including a lower ADR [21,22]. While $94.4 \%$ of our colonoscopy preparations were good, the remaining $5.6 \%$ were either suboptimal or poor, as result of decreased patient compliance, failure to comprehend and follow through with the instructions provided. It is interesting to note, however, that a higher ADR $(P=0.014)$ and PDR $(25.7 \%$; $P=0.007)$ were found for suboptimal bowel preparation. This association has been found in only a handful of other studies, and multiple reasons have been hypothesized for an explanation; residual stool in a suboptimal bowel preparation may attach to mucus caps of serrated polyps, allowing for better visualization. Additional washing by the endoscopist results in a higher attention 
- Table 2 Distribution of PDR and ADR

\begin{tabular}{|c|c|c|c|c|c|}
\hline Variables & Total $(\mathrm{N}=1985)$ & PDR (N = 355); n (\%) & $P$ value (PDR) & ADR (N= 197); n (\%) & $P$ value (ADR) \\
\hline - Age (years) \pm S.D. & $47.8 \pm 16.2$ & \multirow[t]{2}{*}{-} & \multirow[t]{2}{*}{ - } & \multirow[t]{2}{*}{-} & \multirow[t]{2}{*}{-} \\
\hline - Median age (range) & $48.0(19-88)$ & & & & \\
\hline \multicolumn{6}{|l|}{ Gender } \\
\hline - Male & $1172(59.0)$ & $217(18.5)$ & \multirow[t]{2}{*}{0.378} & $120(10.2)$ & \multirow[t]{2}{*}{0.574} \\
\hline - Female & $813(41.0)$ & $138(17.0)$ & & $77(9.5)$ & \\
\hline \multicolumn{6}{|l|}{ Age (years) } \\
\hline . $\geq 50$ & $934(47.1)$ & $232(24.8)$ & \multirow[t]{2}{*}{$<0.001^{1}$} & $140(15.0)$ & \multirow[t]{2}{*}{$<0.001^{1}$} \\
\hline . $<50$ & $1051(52.9)$ & $123(11.7)$ & & $57(5.4)$ & \\
\hline \multicolumn{6}{|l|}{ Bowel preparation } \\
\hline - Good & $1873(94.4)$ & $336(17.9)$ & \multirow[t]{3}{*}{$0.007^{1}$} & $183(9.8)$ & \multirow[t]{3}{*}{$0.014^{1}$} \\
\hline - Suboptimal & $70(3.5)$ & $18(25.7)$ & & $13(18.6)$ & \\
\hline - Poor & $42(2.1)$ & $1(2.4)$ & & $1(2.4)$ & \\
\hline \multicolumn{6}{|c|}{ Endoscopist procedural experience (10 years) } \\
\hline . $<500$ & $208(10.5)$ & $45(21.6)$ & \multirow[t]{4}{*}{$0.020^{1}$} & $30(14.4)$ & \multirow[t]{4}{*}{$0.049^{1}$} \\
\hline . 500-999 & $458(23.1)$ & $63(13.8)$ & & $41(9.0)$ & \\
\hline . $1000-1500$ & $644(32.4)$ & $111(17.2)$ & & $53(8.2)$ & \\
\hline - $>1500$ & $675(34.0)$ & $136(20.1)$ & & $73(10.8)$ & \\
\hline \multicolumn{6}{|c|}{ Endoscopist experience (years) } \\
\hline . $\leq 10$ & $863(43.5)$ & $178(20.6)$ & \multirow[t]{2}{*}{$0.005^{1}$} & $101(11.7)$ & \multirow[t]{2}{*}{$0.020^{1}$} \\
\hline . $>10$ & $1122(56.5)$ & $177(15.8)$ & & $96(8.6)$ & \\
\hline \multicolumn{6}{|c|}{$\begin{array}{l}\text { All categorical variables are reported as numbers (percenta } \\
\text { gorical variables. } \\
\text { PDR, polyp detection rate; ADR, adenoma detection rate. } \\
1 P \text { values are significant }(<0.05) \text {. }\end{array}$} \\
\hline
\end{tabular}

to mucosa, subsequently increasing incidental PDR. Moreover, an excellent preparation may falsely increase confidence of the endoscopist, resulting a decreased quality of inspection [2325].

Multiple previous studies have documented an association of higher PDR and ADR with greater experience of endoscopists. Pace et al. reported increased rates of polyp and adenoma detection with high annual case volumes $(>530)(P<$ 0.001) [26], while another study found more experienced endoscopists were able to detect a higher number of smallersized polyps $(<3 \mathrm{~mm})$, as well as adenomas with advanced histology $(P<0.0001)$ [27]. Hence, the most surprising difference is that our study showed that endoscopists with experience performing $<500$ colonoscopies, had a statistically significant higher PDR (21.6\%; $P=0.02)$ and ADR (14.4\%; $P=0.049)$ as compared to those with experience with $>500$ procedures, corresponding to a significantly higher PDR $(20.6 \% ; P=0.005)$ and ADR (11.7\%; $P=0.02$ ) for endoscopists in practice for $\leq 10$ years. This disparity may be attributed to a higher-volume patient load and efficiency demands for more experienced endoscopists, resulting in a shorter withdrawal time and less meticu- lous examination [28]. Furthermore, endoscopists with less experience are expected to perform a more extensive examination during their training and practice, and hence, they have a greater incidental finding rate. Endoscopist fatigue also should be taken into consideration, since a significant association has been documented between progress of the day/endoscopy shift and reduced PDR [29-31]. As there is contradictory evidence for this postulation [32,33], further investigations to define, measure, and identify factors related to endoscopist fatigue are greatly needed.

Our study has several limitations. Because it was a singlecenter study, the results are limited by external validity. In addition, no numerical or objective documentation about bowel preparation on the BBPS was performed; thus, we recommend modifying regional institutional practices to include such an objective outcome when assessing quality of bowel preparation. We were also unable to quantify the number of continuing-medical-education (CME) meetings attended by our endoscopists. These hands-on educational sessions can increase understanding of polyp morphology and examination techniques, which subsequently results in better colonoscopy performance 
with a higher ADR. This is supported by a report by Adler et al., which showed that the number of CME meetings attended $(P=$ $0.012)$ as well as colonoscopy scope generation $(P=0.001)$ accounted for approximately $40 \%$ of the inter-physician variability for ADR [34]. We consider the generation of instruments used as a strength of our study because the latest generation of wide-angle, high-definition colonoscopes can improve ADR by $22 \%$, as compared with mixed, older endoscopes [35].

\section{Conclusions}

In summary, we report low PDR and ADR, although multifactorial causes may be implicated as discussed above. We strongly urge implementation of a regional screening colonoscopy program and notification of endoscopists about their ADRs and their importance as a quality indicator for colonoscopy. Although our data can be used to provide a baseline for comparison by other regional endoscopists, future multicenter, prospective studies need to be conducted to generate conclusive evidence and establish a baseline PDR and ADR. Further research must be undertaken to evaluate other quality indicators, as a step towards improvement of the overall quality of colonoscopies performed.

\section{Competing interests}

The authors declare that they have no conflict of interest.

\section{References}

[1] Bray F, Ferlay J, Soerjomataram I et al. Global cancer statistics 2018: GLOBOCAN estimates of incidence and mortality worldwide for 36 cancers in 185 countries. CA Cancer J Clin 2018; 68: 394-424

[2] Bretthauer M, Kalager M. Mass Medical Soc. Colonoscopy as a triage screening test. N Engl J Med 2012; 366: 759-760

[3] Garborg K, Holme $\varnothing$, Løberg M et al. Current status of screening for colorectal cancer. Ann Oncol 2013; 24: 1963-1972

[4] Shaukat A, Mongin SJ, Geisser MS et al. Long-term mortality after screening for colorectal cancer. N Engl J Med 2013; 369: 1106-1114

[5] Nishihara R, Wu K, Lochhead P et al. Long-term colorectal-cancer incidence and mortality after lower endoscopy. N Engl J Med 2013; 369: 1095-1105

[6] Zauber AG, Winawer SJ, O'Brien MJ et al. Colonoscopic polypectomy and long-term prevention of colorectal-cancer deaths. N Engl J Med 2012; 366: 687-696

[7] Qaseem A, Denberg TD, Hopkins RH et al. Screening for colorectal cancer: a guidance statement from the American College of Physicians. Ann Intern Med 2012; 156: 378-386

[8] Rex DK, Johnson DA, Anderson JC et al. American College of Gastroenterology guidelines for colorectal cancer screening 2008. Am J Gastroenterol 2009; 104: 739-750

[9] Kaminski MF, Thomas-Gibson S, Bugajski M et al. Performance measures for lower gastrointestinal endoscopy: a European Society of Gastrointestinal Endoscopy (ESGE) quality improvement initiative. Endoscopy 2017; 49: 378-397

[10] Kaminski MF, Regula J, Kraszewska E et al. Quality indicators for colonoscopy and the risk of interval cancer. N Engl J Med 2010; 362: 1795-1803
[11] Corley DA, Jensen CD, Marks AR et al. Adenoma detection rate and risk of colorectal cancer and death. N Engl J Med 2014; 370: 12981306

[12] Rex DK, Schoenfeld PS, Cohen J et al. Quality indicators for colonoscopy. Gastrointest Endosc 2015; 81: 31-53

[13] Lai E], Calderwood AH, Doros G et al. The Boston bowel preparation scale: a valid and reliable instrument for colonoscopy-oriented research. Gastrointest Endosc 2009; 69: 620-625

[14] Cooper GS, Chak A, Koroukian S. The polyp detection rate of colonoscopy: a national study of Medicare beneficiaries. Am J Med 2005; 118: 1413.e1411-1413.e1414

[15] Rehman KU, Qureshi MO, Khokhar N et al. Quality of colonoscopy and spectrum of lower gastrointestinal disease as determined by colonoscopy. J Coll Physicians Surg Pak 2015; 25: 478-481

[16] Mohammad S, Rind GH, Shah IA et al. Colonoscopy Findings: A Single Institution Study from Pakistan. Cureus 2019; 11: e6167

[17] Wolf AM, Fontham ET, Church TR et al. Colorectal cancer screening for average-risk adults: 2018 guideline update from the American Cancer Society. CA Cancer J Clin 2018; 68: 250-281

[18] Center for Disease Control and Prevention. Colorectal (Colon) Cancer. 2020: Available from (Accessed 2020 5th July): https://www.cdc.gov/ cancer/colorectal/basic_info/screening/index.htm\#: :text=Screening\%20Guidelines,if\%20they\%20should\%20be\%20screened

[19] Rex DK. Colonoscopy: a review of its yield for cancers and adenomas by indication. Am J Gastroenterol 1995; 90: 353-365

[20] Lee TJ, Rutter MD, Blanks RG et al. Colonoscopy quality measures: experience from the NHS Bowel Cancer Screening Programme. Gut 2012; 61: 1050-1057

[21] Johnson DA, Barkun AN, Cohen LB et al. Optimizing adequacy of bowel cleansing for colonoscopy: recommendations from the US multi-society task force on colorectal cancer. Gastroenterology 2014; 147: 903-924

[22] Froehlich F, Wietlisbach V, Gonvers J-J et al. Impact of colonic cleansing on quality and diagnostic yield of colonoscopy: the European Panel of Appropriateness of Gastrointestinal Endoscopy European multicenter study. Gastrointest Endosc 2005; 61: 378-384

[23] Adike A, Buras MR, Gurudu SR et al. Is the level of cleanliness using segmental Boston bowel preparation scale associated with a higher adenoma detection rate? Ann Gastroenterol 2018; 31: 217-223

[24] Calderwood AH, Thompson KD, Schroy PC et al. Good is better than excellent: bowel preparation quality and adenoma detection rates. Gastrointest Endosc 2015; 81: 691-699.e691

[25] Anderson JC, Butterly LF, Robinson CM et al. Impact of fair bowel preparation quality on adenoma and serrated polyp detection: data from the New Hampshire colonoscopy registry by using a standardized preparation-quality rating. Gastrointest Endosc 2014; 80: 463470

[26] Pace D, Borgaonkar M, Lougheed M et al. Effect of Colonoscopy Volume on Quality Indicators. Can J Gastroenterol and Hepatol 2016; 2016: 2580894

[27] Solís-Muñoz P, Solís-Herruzo JA, Rodríguez-Muñoz S. Experience of the endoscopist increases detection rates of smaller size and higher histological grade polyps. J Gastroenterol Hepatol 2014; 29: 12371241

[28] Almario CV, Spiegel BM. Does endoscopist fatigue impact adenoma detection rate? A review of the evidence to date Gastrointest Endosc 2017; 85: 611-613

[29] Chan MY, Cohen H, Spiegel BM. Fewer polyps detected by colonoscopy as the day progresses at a Veteran's Administration teaching hospital. Clin Gastroenterol Hepatol 2009; 7: 1217-1223 ; quiz 1143

[30] Kaneshiro M, Ho A, Chan M et al. Colonoscopy yields fewer polyps as the day progresses despite using social influence theory to reverse the trend. Gastrointest Endosc 2010; 72: 1233-1240 
[31] Long MD, Martin C, Sandler RS et al. Reduced polyp detection as endoscopy shift progresses: experience with screening colonoscopy at a tertiary-care hospital. J Clin Gastroenterol 2011; 45: 253-258

[32] Lee A, Jensen CD, Marks AR et al. Endoscopist fatigue estimates and colonoscopic adenoma detection in a large community-based setting. Gastrointest Endosc 2017; 85: 601-610.e602

[33] Gurudu SR, Ratuapli SK, Leighton JA et al. Adenoma detection rate is not influenced by the timing of colonoscopy when performed in halfday blocks. Am J Gastroenterol 2011; 106: 1466-1471
[34] Adler A, Wegscheider K, Lieberman D et al. Factors determining the quality of screening colonoscopy: a prospective study on adenoma detection rates, from 12134 examinations (Berlin colonoscopy project 3, BECOP-3). Gut 2013; 62: 236-241

[35] Adler A, Aminalai A, Aschenbeck J et al. Latest generation, wide-angle, high-definition colonoscopes increase adenoma detection rate. Clin Gastroenterol Hepatol 2012; 10: 155-159 